\title{
Microbial production of dicarboxylic acids from edible plants and milk using GC-MS
}

\author{
Rajinder Kaur ${ }^{1}$, Rajanbir Kaur ${ }^{1}$, Anket Sharma ${ }^{1}$, Vinod Kumar ${ }^{2 *}$, Manik Sharma ${ }^{1}$, Renu Bhardwaj ${ }^{1}$ \\ and Ashwani Kumar Thukral ${ }^{1 *}$
}

\begin{abstract}
Objective: The present experiment was designed to assess the contents of organic acids such as citric acid, succinic acid, fumaric acid, and malic acid in edible food plants and milk under the influence of Eschericia coli.

Methods: Gas chromatography-mass spectrometry (GC-MS) was used to estimate the contents of organic acids in edible plants and milk. Two microliters of samples was injected into the GC-MS, and the contents of organic acids were computed using standard curves.

Results: Maximum citric content (204 mg/g DW, 24 h E. coli treatment) was observed in tomato followed by papaya (175 mg/g DW). Papaya and grapes (715 and $504 \mathrm{mg} / \mathrm{g}$ DW, $24 \mathrm{~h}$ E. coli treatment respectively) can be good sources of succinic acid. Malic acid content was highest in E. coli-treated milk (168 mg/g DW). In general, there was a decrease in average citric acid and increase in succinic acid contents in the food sources tested on treatment with E. coli.

Conclusion: It was found that among the tested raw food items and milk, with or without E. coli inoculation, tomato and papaya hold a good potential for citric acid production, grapes and papaya for succinic acid, and milk for malic acid production. The study can be a basis for utilization of vegetables, fruits, and milk for the production of dicarboxylic acids to boost the agrarian economy.
\end{abstract}

Keywords: E. coli, Food plants, Milk, Organic acids, Multivariate statistical techniques

\section{Introduction}

Organic acid production using microbial processes for industrial use is finding increasing attention worldwide (Sauer et al. 2008). Tricarboxylic acid cycle (TCA) operative in living organisms produces citric acid, succinic acid, fumaric acid, and malic acid as intermediates during the process of respiration. All these acids are extensively used in industry. Out of these, only citric acid is largely produced using microbial technology. Attempts are underway for the microbial production of other acids. The annual production of citric acid is 1.6 million tons, and it is mainly produced from the fermentation of glucose, sucrose or beet, and cane molasses using the fungi Aspergillus niger or Yarrowia lipolytica (Berovic and Legisa 2007; Gonçalves et al. 2014). The annual

\footnotetext{
* Correspondence: vinodverma507@gmail.com; akthukral.gndu@gmail.com ${ }^{2}$ Department of Botany, DAV University, Sarmastpur, Jalandhar, Punjab 144012, India

${ }^{1}$ Department of Botanical and Environmental Sciences, Guru Nanak Dev University, Amritsar, Punjab 143005, India
}

production of succinic acid is 1600 tons. Presently, succinic acid is largely produced by the catalytic hydrogenation of maleic anhydride, a fossil-based chemical. It has the potential to replace maleic anhydride as a raw material for many chemical industries, and its projected market is 270,000 tons (Sauer et al. 2008). The annual production of fumaric acid is 240,000 tons. The projected annual market of fumaric acid is 350,000 tons by 2020 (www.grandviewresearch.com). Malic acid is widely used as a food additive and also used in pharmaceutical and polymer industries. Malic acid is chemically produced by the hydration of maleic or fumaric acids (Moon et al. 2008). The demand for malic acid is expected to increase from 10,000 tons in 2008 to more than 200,000 tons (Sauer et al. 2008).

Escherichia coli is one of the preferred bacteria for studies on the energetics and regulation of respiration (Unden and Bongaerts 1997). Due to multitude of primary dehydrogenases, quinones, and terminal reductases, a large 
variability in the composition of the respiratory chains is observed. Since $E$. coli is a natural habitant of human intestines, the present study was designed to assess the effects of E. coli at $0 \mathrm{~h}, 24 \mathrm{~h}$, and $72 \mathrm{~h}$ treatments on food plants such as Triticumaestivum, Zea mays, Vigna mungo, Lens culinaris, Pisumsativum, Phaseolus vulgaris, Cicer arietinum (black gram), Cicer arietinum (white gram), Solanum tuberosum, Solanum lycopersicum, Brassica oleracea, Malus pumila, Musa paradisiaca, Vitisvinifera, Carica papaya, and milk. The organic acids such as citric acid, succinic acid, fumaric acid, and malic acid were quantified in the food items and milk by using GC-MS. The results were analyzed by using various multivariate techniques such as cluster analysis (CA), factor analysis (CABFAC), and non-metric multidimensional scaling (NMDS).

\section{Methods}

\section{E. coli culture}

The bacterial strain of E. coli $\mathrm{K}-12$ was procured from Microbial Type Culture Collection (MTCC) facility, Chandigarh, India. The culture was revived using Luria Bertani broth (composition used for the broth: casein enzymic hydrolysate $10 \mathrm{~g} / \mathrm{L}$, yeast extract $5 \mathrm{~g} / \mathrm{L}$, sodium chloride $10 \mathrm{~g} / \mathrm{L}$, and $\mathrm{pH}$ was adjusted to 7.3 ) and incubated in orbital shaker for $24 \mathrm{~h}$ at $37^{\circ} \mathrm{C}$. The chemicals and biochemicals were purchased from Himedia (India). The culture was diluted with the fresh medium in order to obtain the cell density of $10^{7} \mathrm{cfu} / \mathrm{ml} .0 .1 \mathrm{ml}$ of the inoculum was taken from the diluted culture to inoculate the experimental media.

\section{Sample preparation}

Two grams of each of the edible food source was taken in $100 \mathrm{ml}$ of distilled water, autoclaved at $121{ }^{\circ} \mathrm{C}$, inoculated with $100 \mu \mathrm{l}$ of $E$. coli culture for 24 and $72 \mathrm{~h}$, and kept in a BOD incubator at $37^{\circ} \mathrm{C}$. One hundred milliliters of milk was taken in a flask, autoclaved at $121{ }^{\circ} \mathrm{C}$, inoculated with $100 \mu \mathrm{l}$ of E. coli culture for 24 and $72 \mathrm{~h}$, and kept in BOD incubator at $37{ }^{\circ} \mathrm{C}$. All the samples were filtered with Whatman filterpaper\#1 after 24 and $72 \mathrm{~h}$ and kept in a refrigerator for GC-MS analysis.

\section{Organic acid determination by GC-MS}

The determination of organic acids was done by following the protocol described by Sharma et al. (2016). The organic acids were extracted from $1 \mathrm{ml}$ of the oven-dried samples by the addition of $0.5 \mathrm{~N} \mathrm{HCl}$ $(0.5 \mathrm{ml})$ and $0.5 \mathrm{ml}$ of methanol. After that, the samples were shaken for $3 \mathrm{~h}$ proceeded by centrifugation $(12,000 \mathrm{rpm} ; 10 \mathrm{~min})$. The supernatant, methanol $(300 \mu \mathrm{l})$, and $50 \%$ sulfuric acid $(100 \mu \mathrm{l})$ were added and incubated for overnight in water bath at $60{ }^{\circ} \mathrm{C}$. After cooling to $25{ }^{\circ} \mathrm{C}, 800 \mu \mathrm{l}$ of chloroform and $400 \mu \mathrm{l}$ of distilled water were added to the supernatant followed by vortexing for $1 \mathrm{~min}$. The lower layer of chloroform was used to determine the organic acid contents.

\section{Conditions of GC-MS}

Helium was used as the carrier gas, and the starting column temperature was set at $50{ }^{\circ} \mathrm{C}$, stopped for $1 \mathrm{~min}$ which was increased to $125^{\circ} \mathrm{C}$ at $25^{\circ} \mathrm{C} / \mathrm{min}$, followed by additional increment to $300{ }^{\circ} \mathrm{C}$ at $10{ }^{\circ} \mathrm{C} / \mathrm{min}$, and detained for $15 \mathrm{~min}$. Injection temperature was $250{ }^{\circ} \mathrm{C}$, injection mode was split, gas flow in the column was $1.7 \mathrm{ml} / \mathrm{min}$, and analytical column DB-5ms was used. MS conditions are as follows: Ion source temperature was fixed at $200^{\circ} \mathrm{C}$ and interface temperature was $280^{\circ}$ $\mathrm{C}$, solvent cut time was $3 \mathrm{~min}$, and detector gain mode was relative. The sample preparation procedure resulted in the derivatization of organic acids, and the concentrations of citric acid trimethylester, succinic acid dimethyester, fumaric acid dimethyester, and malic acid dimethyester were determined by using standard curves.

\section{Statistical analysis}

All the experiments were performed in triplicate, and the data were presented as mean $\pm \mathrm{SD}$. The data was also analyzed by using multivariate techniques. Two-way analysis of variance (ANOVA) and post hoc Tukey's honestly significant difference (HSD) test were applied to the contents of different organic acids with respect to the duration of $E$. coli treatment. Similarities among the species in n-dimensional space were computed using Ward's method of cluster analysis with Euclidean distance as distance measure. Factor analysis (CABFAC) was done by regressing the variables (organic acids) on environmental variable (hours of E. coli treatment) and varimax rotation. Factor analysis brings out common variables governed by the same factor. A loading of a factor of magnitude $(0.7$ or -0.7$)$ or more was treated to be significant.

Non-metric multidimensional scaling (NMDS) is a multivariate technique of data reduction. In NMDS, ranked differences among the points in multidimensional space are maintained in a two- or three-dimensional space using a similarity measure, correlation in the present study. The environmental variable taken was $E$. coli treatment. In the present analysis, NMDS software developed by Taguchi and Oono (2005) was used. The other software used were PAST3 (Imbrie 1971; Klovan and Imbrie 1971; Sieger et al. 1999), MINITAB-14, and self-coded software in Microsoft Excel.

\section{Results and discussion}

Table 1 shows mean $\pm \mathrm{SD}, F$-ratios of two-way analysis of variance, and Tukey's HSD values of organic acids with respect to different durations of $E$. coli treatment. 


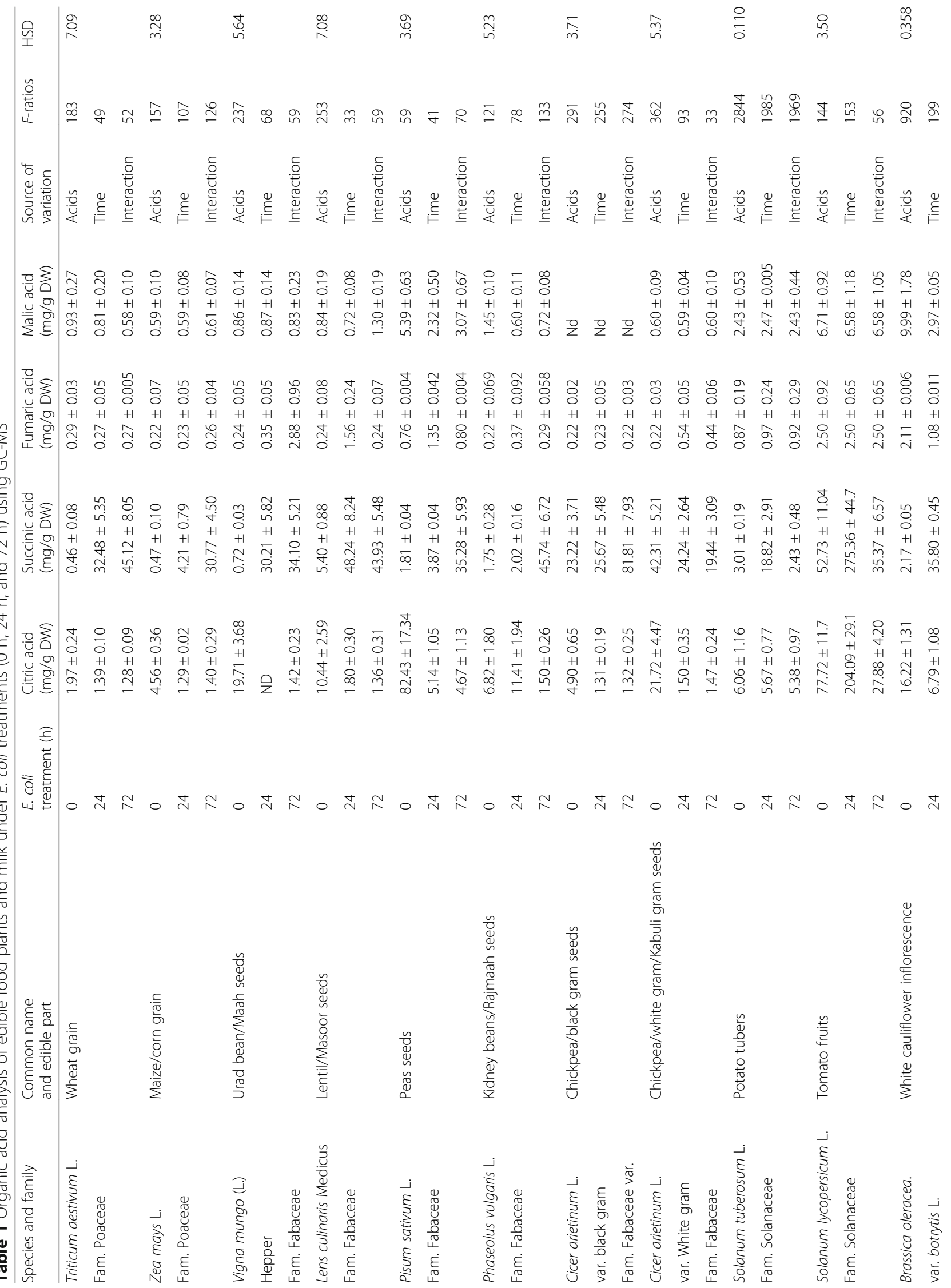




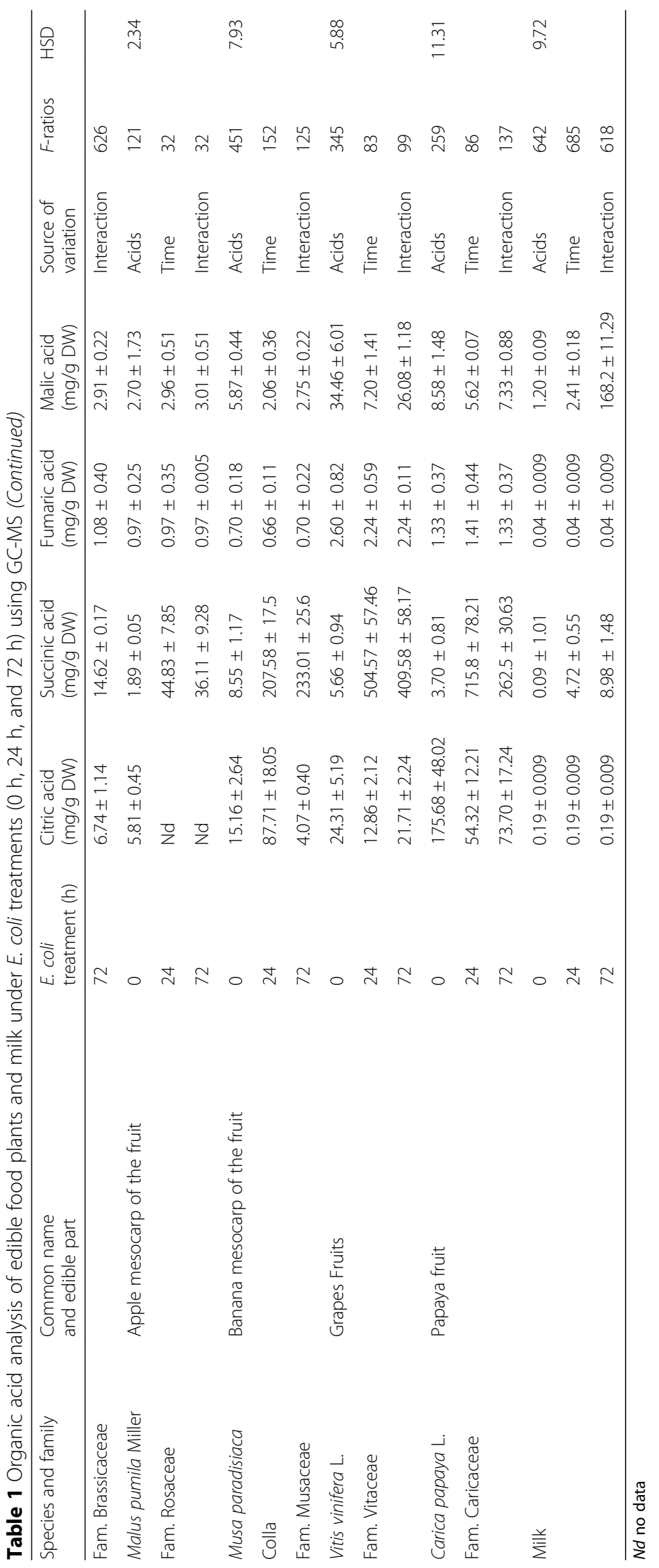


Among the analyzed samples, citric acid content on dry weight basis was found to be maximum in tomato (204 $\mathrm{mg} / \mathrm{g}$ in $24 \mathrm{~h}$ treatment), papaya $(175 \mathrm{mg} / \mathrm{g})$, banana $(87 \mathrm{mg} / \mathrm{g})$, pea $(82 \mathrm{mg} / \mathrm{g})$, and potato $(77 \mathrm{mg} / \mathrm{g}) . E$. coli treatment decreased average citric acid content of cereals and pulses. E. coli fermentation increased the succinic acid content in cereals, pulses, vegetables, and fruits tested except for white gram. Papaya, grapes, tomato, and banana yielded 175, 504, 275, and $233 \mathrm{mg} / \mathrm{g}$ DW of succinic acid on inoculation with $E$. coli. In $S$. lycopersicum and $M$. paradisiaca, the citric acid content initially increased followed by a decrease on $E$. coli treatment. There was no significant difference in fumaric acid contents in the samples inoculated with E. coli. Malic acid content was increased in milk with E. coli inoculation. However, no specific trend was found for the other analyzed food plants. In 11 out of 15 cereals, pulses, vegetables, and fruits, the average citric acid content was reduced on inoculation with $E$. coli. The average values of fumaric and malic acid contents were recorded to be very low in the cereals, pulses, vegetables, and fruits (Figs. 1 and 2). Milk yielded the highest malic acid content on $E$. coli treatment $(168 \mathrm{mg} / \mathrm{g})$.

In vegetables, the average citric acid and succinic acid contents were found to be maximum for $24 \mathrm{~h}$ duration on $E$. coli treatment and decreased after $72 \mathrm{~h}$ with $E$. coli treatment. The average values of fumaric acid and malic acid contents were found to be very low in the vegetables (Fig. 3). In fruits, the average citric acid content was reduced with inoculation of $E$. coli, whereas the average succinic acid content was found to be maximum for 24 h duration of $E$. coli treatment. The average fumaric

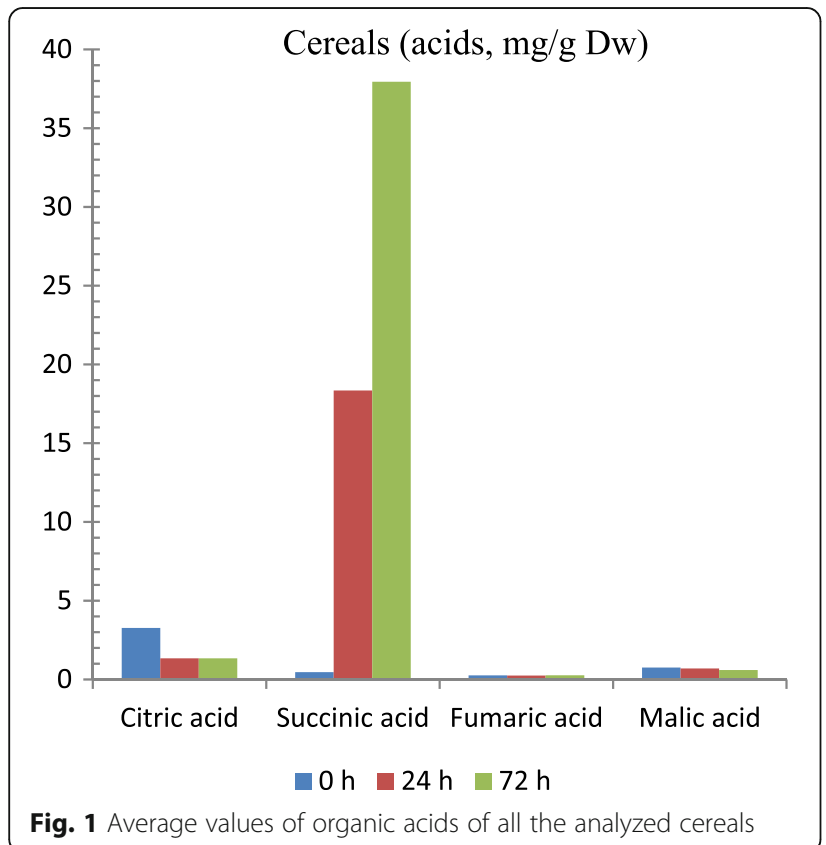

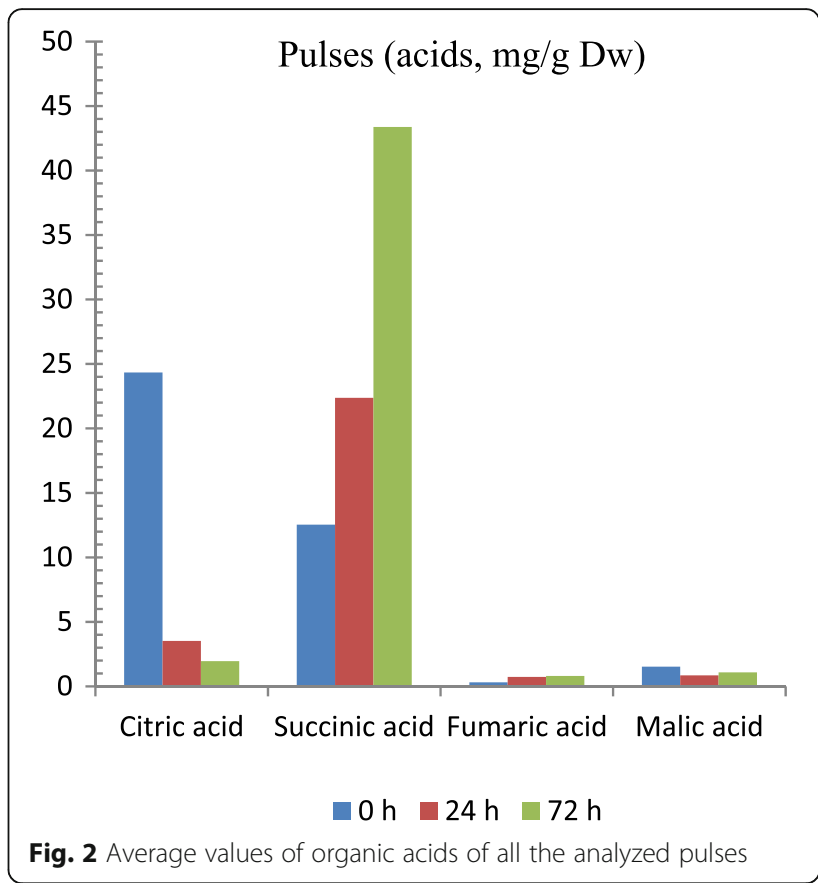

acid and malic acid contents were found low in the fruits (Fig. 4). In milk, malic acid content was enhanced under E. coli treatment with respect to the control (Fig. 5). Citric acid and fumaric acid contents were recorded very low in milk. Analysis of data by using two-way ANOVA and Tukey's HSD test showed significant differences for citric acid $\left(F_{\text {acids }}, F_{\text {time }}\right.$, and $\left.F_{\text {acids } \times \text { time }} p<0.05\right)$, succinic acid $\left(F_{\text {acids }}, F_{\text {time }}\right.$, and $\left.F_{\text {acids } \times \text { time }} p<0.05\right)$, fumaric acid $\left(F_{\text {acids }}, F_{\text {time }}\right.$, and $F_{\text {acids }} \times$ time $\left.p<0.05\right)$, and malic acid $\left(F_{\text {acids }}, F_{\text {time }}\right.$, and $\left.F_{\text {acids } \times \text { time }} p<0.05\right)$ in different edible plants.

Cluster analysis (CA) was applied to the contents of different organic acids (Fig. 6). C. papaya and $V$. vinifera are included in the same cluster, and both are fruits. The

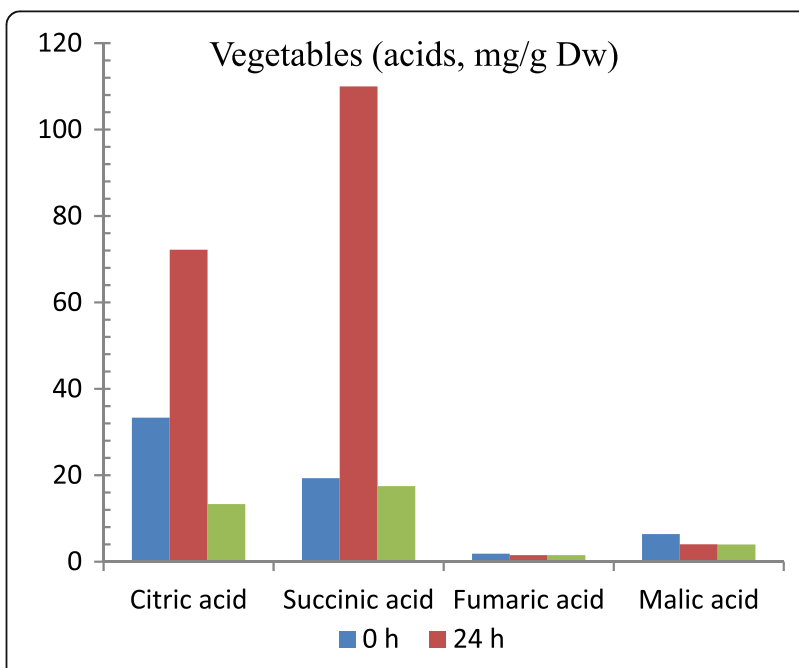

Fig. 3 Average values of organic acids for all the analyzed vegetable 


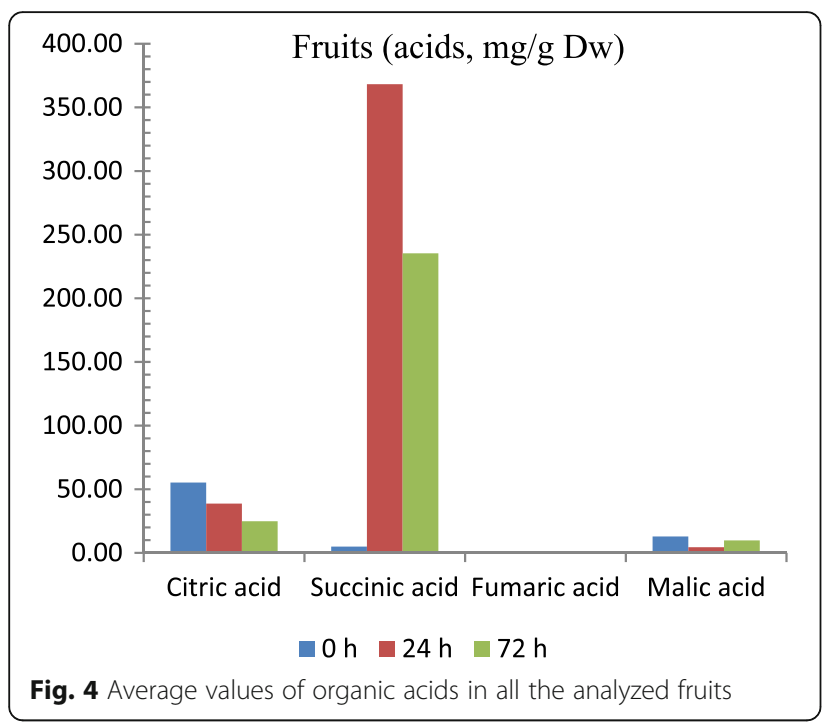

pulses, C. arietinum w.g, C. arietinum b.g, and L. culinaris, are included in the same cluster and had close proximities with each other. B. oleracea and P. sativum are included in the same cluster, and both are vegetables. CABFAC factor analysis yielded segregation of untreated and $E$. coli-treated organic acid variables in two different factors (Fig. 7). In C. arietinum, however, both the treatments are represented in the same first factor implying that there is another factor governing acid formation in these pulses. In grapes, sugar content may be the governing factor. In milk, the segregation of the factors was different, and lactose present in milk could be the deciding factor. First three factors explained $99.87 \%$ of the total variance, and the Eigen value was more than one for the first three factors (Table 2). This factor is contributed by E. coli. Both CABFAC scatter plot and NDMS

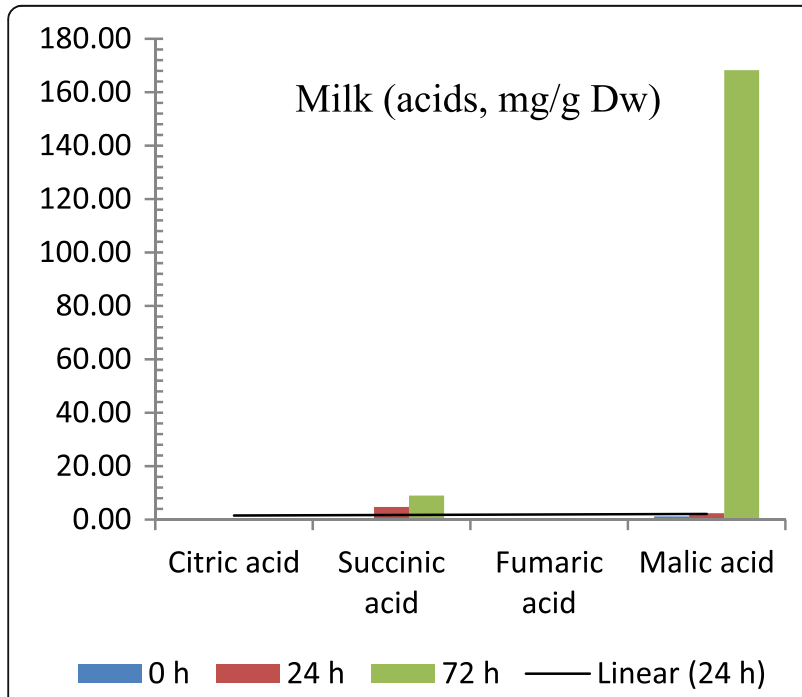

Fig. 5 Average values of organic acids in milk scatter plot reveal three points (point no. $48=$ milk $72 \mathrm{~h}$, $46=$ milk $0 \mathrm{~h}$, and $40=$ grapes $0 \mathrm{~h}$ ) segregated from the main group (Figs. 8 and 9). Since the stress in NMDS Shepard curve (Fig. 9) is 0.03785, i.e., less than 0.05, the data shows a good fit to NMDS. As also seen in the factors, chemical composition of these items might be segregating them from the other items.

E. coli are Gram-negative bacteria mainly occupying the lower intestinal tract of humans and animals and are regularly excreted into the environment by feces or wastewater discharge. The existence of E. coli in the environmental waters has been measured as a marker of fecal pollution (Jang et al. 2017). The wild strain of $E$. coli under anaerobic conditions produces acetate, formate, ethanol, and succinate, whereas aerobically succinate is formed as an intermediate of TCA cycle. E. coli has been used for the production of succinic acid (Thakker et al. 2013; Skorokhodova et al. 2013) under aerobic conditions using raffinose, galactose, sucrose, and stachyose. Bioenergetics of $E$. coli involve aerobic and anaerobic respiration and fermentation, which require different carriers to transport different substrates and products across membranes. Succinic, fumaric, and malic acids play different roles in different respiratory pathways (Unden and Bongaerts 1997). In aerobic respiration, careers mediate the uptake of succinic acid. However, in anaerobic process, exchange of fumarate with succinate, uptake of fumarate, and efflux of succinate occurs.

In the present study, fruits and vegetables, especially papaya, grapes, and tomato, were found to be good sources of succinic acid. E. coli is a preferred bacterium for study of succinate production technology due to its known genomics and proteomics (Thakker et al. 2012). Nghiem et al. (2017) suggested that there can be two metabolic pathways for the production of succinic acid from glucose. In the TCA pathway, succinic acid is an intermediate of oxidation of glucose via citrate. On the other hand, succinic acid is more reduced molecule than glucose, and a reduction pathway for its production is:

$$
\begin{aligned}
& 7 \mathrm{C}_{6} \mathrm{H}_{12} \mathrm{O}_{6}+6 \mathrm{CO}_{2} \rightarrow 12 \mathrm{C}_{4} \mathrm{H}_{4} \mathrm{O}_{4} \text { (succinic acid) } \\
& +6 \mathrm{H}_{2} \mathrm{O}
\end{aligned}
$$

Microbial production of succinic acid can be achieved using Actinobacillus succinogenes, Mannheimia succinciproducens, E. coli, Actinobacillus succinogenes, and Anaerobiospirillum succiniciproducens from glucose, molasses, and wheat (Sauer et al. 2008). Toker et al. (2004) analyzed organic acid contents in the fresh parts of different varieties of $C$. arietinum. They reported the highest organic acid content to be that of succinic acid followed by malic acid, the minimum being citric acid. The glycolysis of glucose produces pyruvate which is then metabolized to yield 


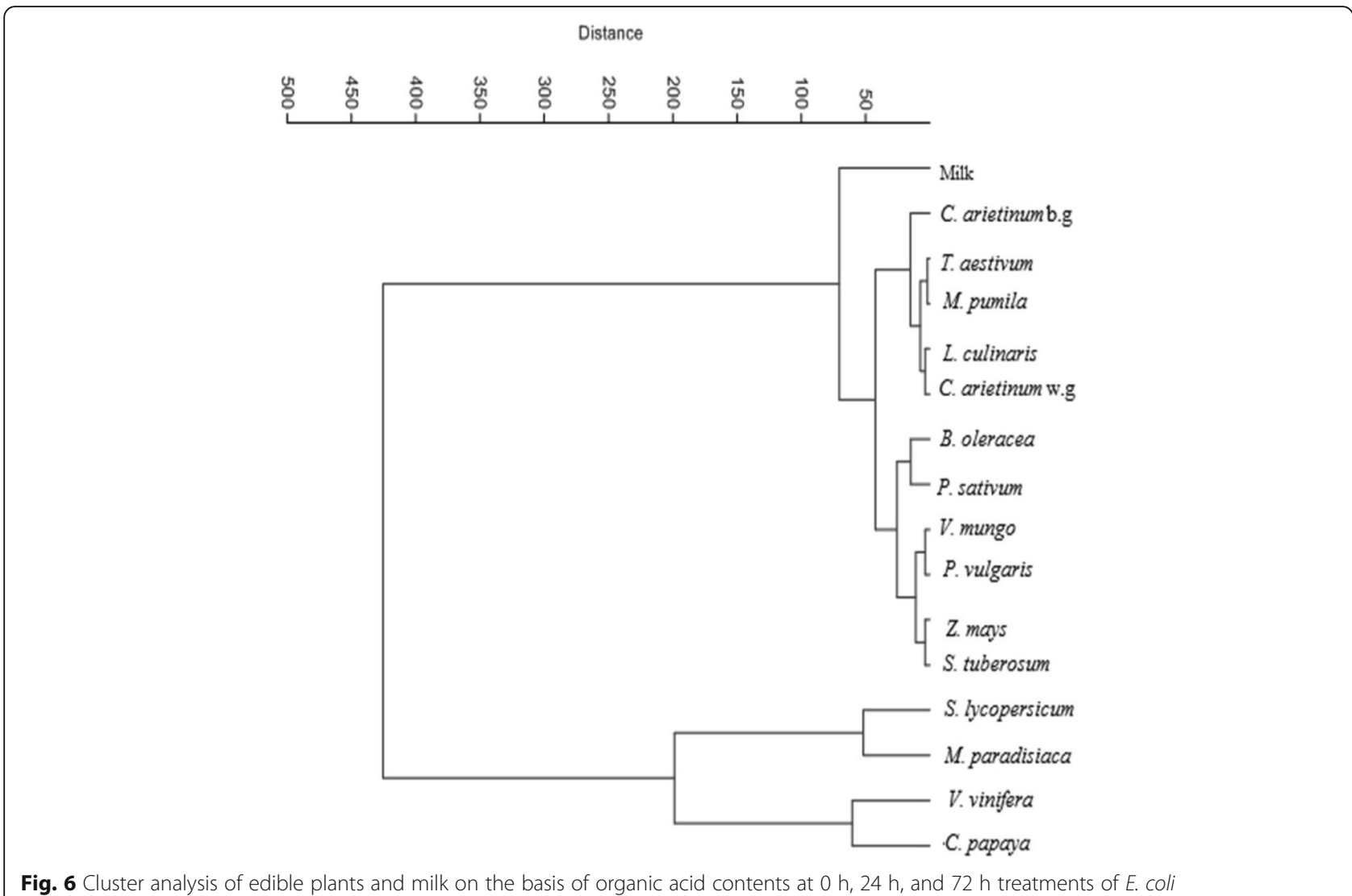

Fig. 6 Cluster analysis of edible plants and milk on the basis of organic acid contents at 0 h, 24 h, and 72 h treatments of E. coli

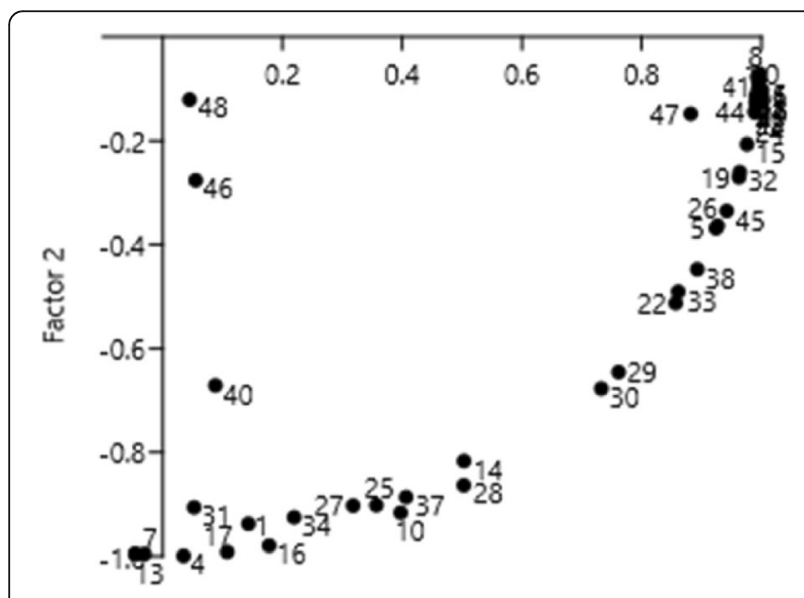

Factor 1

Fig. 7 Varimax scatter plot of organic acid contents of raw food items and milk under in E. coli cultures for $0 \mathrm{~h}, 24 \mathrm{~h}$, and $72 \mathrm{~h}$ treatments using CABFAC factor analysis. (Environmental variable $=$ time of treatment in hours) one or more end products such as lactate, acetate, ethanol, formate, malate, succinate, hydrogen, and carbon dioxide (Förster and Gescher 2014).

In the present study, fumaric acid was not produced or enhanced to be exploited on an industrial scale with or without E. coli treatment. TCA cycle produces fumaric acid as an intermediate from glucose metabolism. Fumaric acid is used in the manufacture of polyesters, resins, inks, and as an animal feed and a food additive to tortilla, fruit juice, wines, etc. In view of the increasing cost of production, microbiological methods offer an economically feasible solution.

$$
\begin{aligned}
& \mathrm{C}_{6} \mathrm{H}_{12} \mathrm{O}_{6} \\
& \quad+2 \mathrm{CO}_{2}\left(\text { from } \mathrm{CaCO}_{3}\right) \rightarrow 2 \mathrm{C}_{4} \mathrm{H}_{4} \mathrm{O}_{4} \text { (fumaric acid) } \\
& \quad+2 \mathrm{H}_{2} \mathrm{O}
\end{aligned}
$$

The reductive pathway for fumaric acid from glucose occurs via carboxylation of pyruvate to oxaloacetate, then to malate and fumerate. The reductive pathway is catalyzed by pyruvate carboxylase under aerobic conditions (Das et al. 2017). Commercial production of fumaric acid is done from maleic anhydride using vanadyl pyrophosphate as a catalyst (Martin-Dominguez et al. 2018). 
Table 2 CABFAC factor analysis of edible food plants and milk on the basis of organic acid contents for 0 h, $24 \mathrm{~h}$, and $72 \mathrm{~h}$ under $\mathrm{E}$. coli treatments. Values in italics represent significant factor

\begin{tabular}{|c|c|c|c|c|c|}
\hline No. & Food source & Treatment (h) & Factor 1 & Factor 2 & Factor 3 \\
\hline 1 & Triticum aestivum & 0 & 0.140 & -0.930 & 0.300 \\
\hline 2 & & 24 & 0.993 & -0.112 & 0.020 \\
\hline 3 & & 72 & 0.995 & -0.097 & 0.010 \\
\hline 4 & Zea mays & 0 & 0.035 & -0.999 & 0.011 \\
\hline 5 & & 24 & 0.924 & -0.369 & 0.098 \\
\hline 6 & & 72 & 0.993 & -0.115 & 0.015 \\
\hline 7 & Vigna mungo & 0 & -0.031 & -0.996 & -0.074 \\
\hline 8 & & 24 & 0.997 & -0.071 & 0.029 \\
\hline 9 & & 72 & 0.991 & -0.115 & 0.020 \\
\hline 10 & Lens culinaris & 0 & 0.397 & -0.916 & -0.033 \\
\hline 11 & & 24 & 0.994 & -0.107 & 0.011 \\
\hline 12 & & 72 & 0.994 & -0.101 & 0.026 \\
\hline 13 & Pisum sativum & 0 & -0.045 & -0.996 & -0.052 \\
\hline 14 & & 24 & 0.503 & -0.817 & 0.245 \\
\hline 15 & & 72 & 0.976 & -0.207 & 0.071 \\
\hline 16 & Phaseolus vulgaris & 0 & 0.178 & -0.980 & 0.089 \\
\hline 17 & & 24 & 0.108 & -0.992 & -0.064 \\
\hline 18 & & 72 & 0.995 & -0.101 & 0.012 \\
\hline 19 & Cicer arietinum var. black gram & 0 & 0.962 & -0.270 & -0.024 \\
\hline 20 & & 24 & 0.993 & -0.118 & -0.005 \\
\hline 21 & & 72 & 0.997 & -0.083 & -0.001 \\
\hline 22 & Cicer arietinum var. white gram & 0 & 0.857 & -0.513 & -0.041 \\
\hline 23 & & 24 & 0.991 & -0.132 & 0.018 \\
\hline 24 & & 72 & 0.989 & -0.146 & 0.022 \\
\hline 25 & Solanum tuberosum & 0 & 0.357 & -0.902 & 0.236 \\
\hline 26 & & 24 & 0.927 & -0.364 & 0.091 \\
\hline 27 & & 72 & 0.318 & -0.903 & 0.277 \\
\hline 28 & Solanum lycopersicum & 0 & 0.503 & -0.863 & -0.026 \\
\hline 29 & & 24 & 0.761 & -0.645 & -0.050 \\
\hline 30 & & 72 & 0.732 & -0.677 & 0.072 \\
\hline 31 & Brassica oleracea. var. botrytis & 0 & 0.052 & -0.906 & 0.416 \\
\hline 32 & & 24 & 0.964 & -0.260 & 0.060 \\
\hline 33 & & 72 & 0.861 & -0.491 & 0.129 \\
\hline 34 & Malus pumila & 0 & 0.220 & -0.925 & 0.297 \\
\hline 35 & & 24 & 0.995 & -0.076 & 0.066 \\
\hline 36 & & 72 & 0.993 & -0.078 & 0.083 \\
\hline 37 & Musa paradisiaca & 0 & 0.406 & -0.886 & 0.221 \\
\hline 38 & & 24 & 0.893 & -0.448 & -0.036 \\
\hline 39 & & 72 & 0.996 & -0.086 & 0.010 \\
\hline 40 & Vitis vinifera & 0 & 0.088 & -0.671 & 0.736 \\
\hline 41 & & 24 & 0.995 & -0.094 & 0.012 \\
\hline 42 & & 72 & 0.990 & -0.127 & 0.057 \\
\hline 43 & Carica papaya & 0 & -0.046 & -0.995 & -0.069 \\
\hline
\end{tabular}


Table 2 CABFAC factor analysis of edible food plants and milk on the basis of organic acid contents for $0 \mathrm{~h}, 24 \mathrm{~h}$, and $72 \mathrm{~h}$ under $\mathrm{E}$. coli treatments. Values in italics represent significant factor (Continued)

\begin{tabular}{|c|c|c|c|c|}
\hline 44 & 24 & 0.990 & -0.143 & -0.001 \\
\hline 45 & 72 & 0.942 & -0.335 & -0.005 \\
\hline Milk & 0 & 0.055 & -0.276 & 0.960 \\
\hline 47 & 24 & 0.882 & -0.148 & 0.448 \\
\hline 48 & 72 & 0.045 & -0.121 & 0.990 \\
\hline \multicolumn{5}{|c|}{ Variance of first three factors using CABFAC factor analysis } \\
\hline Principal component & \multicolumn{2}{|l|}{ Eigenvalue } & \multicolumn{2}{|l|}{$\%$ variance } \\
\hline । & \multicolumn{2}{|l|}{33.36} & \multicolumn{2}{|l|}{69.50} \\
\hline$\|$ & \multicolumn{2}{|l|}{11.78} & \multicolumn{2}{|l|}{24.54} \\
\hline III & \multicolumn{2}{|l|}{2.79} & \multicolumn{2}{|l|}{5.83} \\
\hline Total & \multicolumn{2}{|l|}{47.93} & \multicolumn{2}{|l|}{99.87} \\
\hline
\end{tabular}

$$
\begin{array}{r}
\mathrm{C}_{4} \mathrm{H}_{2} \mathrm{O}_{3} \text { (maleic anhydride) } \stackrel{\text { Hydrolysis }}{\longrightarrow} \mathrm{C}_{4} \mathrm{H}_{4} \mathrm{O}_{4} \\
\text { (maleic acid) } \stackrel{\text { Isomerisation }}{\rightarrow} \mathrm{C}_{4} \mathrm{H}_{4} \mathrm{O}_{4}
\end{array}
$$

(fumaric acid)

In the present study, highest malic acid content was observed in milk inoculated with E. coli after $72 \mathrm{~h}$. Dobrowolska-Iwanek et al. (2015) compared the juice composition of apple cultivars. It was opined by Martin et al. (2000) that carboxylic acid salts enhance the conversion of lactic acid into propionic acid by ruminant bacteria through succinate-propionate pathway. The concentration of malic acid was found to be maximum $\left(6.58 \mathrm{~g} \mathrm{dm}^{-3}\right)$ in Reinette simirenk cultivar. Wang et al. (2009) observed increase in milk yield in dairy cows fed on fodder supplemented with malic acid. Martínez-González et al. (2015) proved that when the diet of ewes was supplemented with $4 \mathrm{~g}$ malic acid/ $\mathrm{kg}$ diet, their milk production and milk protein contents increased.

\section{Conclusions}

From the present study, it was concluded that tomato and papaya can be used as potential sources for citric acid production. Similarly, E. coli treatment of papaya, grapes, and tomato increases their succinic acid content. Milk on treatment with $E$. coli can be a potential source of malic acid. However, the samples analyzed did not prove to be good sources of fumaric acid. It is also concluded that $E$. coli treatment decreases the citric acid content of $T$. aestivum, $V$. mungo, $L$. culinaris, $P$. sativum, C. arietinum, S. tuberosum, and B. oleracea. The succinic acid content was increased with $E$. coli treatment in all samples except for white gram and milk.

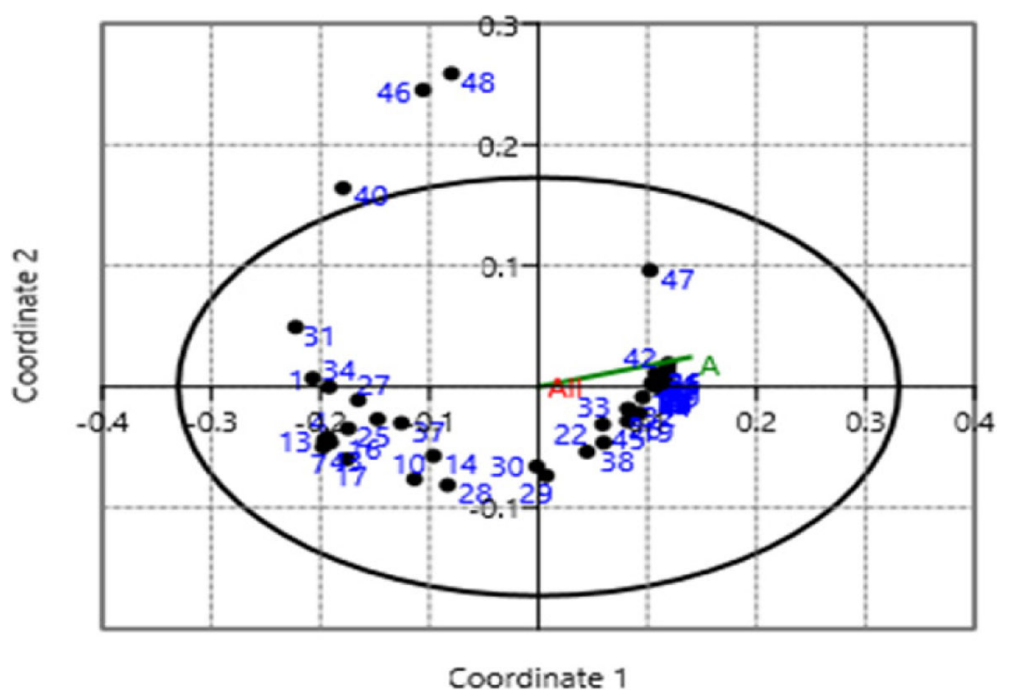

Fig. 8 NMDS scatter plot (95\% eclipse) of organic acid formation in E. coli cultures for 0 h, 24 h, and $72 \mathrm{~h}$ treatments containing raw food items and milk using correlation as a similarity measure. (Environmental variable $=$ time of treatment in hours) 


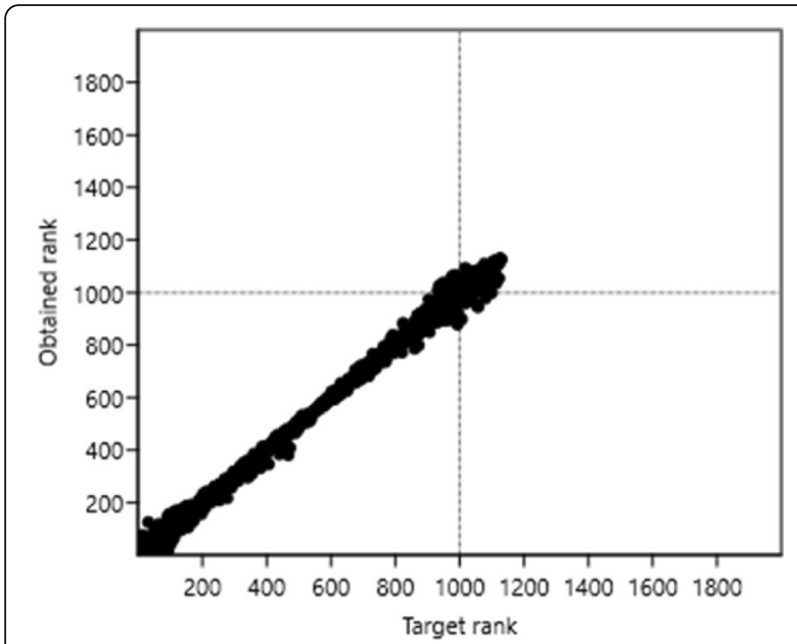

Fig. 9 NMDS Shepard 2-D plot of organic acid formation of raw food and milk for $0 \mathrm{~h}, 24 \mathrm{~h}$, and $72 \mathrm{~h}$ treatments of $\mathrm{E}$. coli cultures (Environmental variable $=$ time of treatment in hours, stress $=0.03785, R^{2}$ for axis $1=0.8091$ and axis $2=0.2267$ )

Malic acid increased in milk on E. coli treatment. Microbial production of dicarboxylic acids, citric acid, succinic acid, and malic acid using microbial technology employing E. coli holds a good potential. The study will provide a baseline data for utilization of surplus vegetables, fruits, and milk for industrial production of dicarboxylic acids and improve the agrarian economy.

\section{Abbreviations}

ANOVA: Analysis of variance; CA: Cluster analysis; FA: Factor analysis; GCMS: Gas chromatography-mass spectrometry; HSD: Honestly significant difference; NMDS: Non-metric multidimensional scaling

\section{Acknowledgements}

No applicable.

\section{Funding}

The work was funded by the University Grants Commission, New Delhi.

\section{Authors' contributions}

This work was carried out in collaboration between all authors. The authors RK and AS collected and analyzed the samples. The authors VK, MS, and AKT carried out literature search and drafted the manuscript. The authors RK, RB, and AKT designed the experiment and statistically analyzed the data. All authors read and approved the final manuscript.

\section{Competing interests}

All authors declare that they have no competing interests.

\section{Publisher's Note}

Springer Nature remains neutral with regard to jurisdictional claims in published maps and institutional affiliations.

Received: 7 August 2018 Accepted: 27 September 2018

Published online: 06 October 2018

\section{References}

Berovic M, Legisa M. Citric acid production. Biotech Annu Rev. 2007;13:303-43. Das RK, Brar SK, Verma M. Fumaric acid: production and application aspects. In: Platform chemical biorefinery. Amsterdam: Elsevier; 2017. p. 133-57.
Dobrowolska-Iwanek J, Gąstoł M, Adamska A, Krośniak M, Zagrodzki P. Traditional versus modern apple cultivars-a comparison of juice composition. Folia Hortic. 2015;27(1):33-41.

Förster AH, Gescher J. Metabolic engineering of Escherichia coli for production of mixed-acid fermentation end products. Front Bioeng Biotechnol. 2014;2:16. https://doi.org/10.3389/fbioe.2014.00016.

Gonçalves FA, Colen G, Takahashi JA. Yarrowia lipolytica and its multiple applications in the biotechnological industry. Sci World J. 2014. https://doi. org/10.1155/2014/476207.

Imbrie JA. New micropaleontological method for quantitative paleoclimatology: application to a late Pleistocene Caribbean core. The Late Cenozoic Glacial Ages. New Haven, CT: Yale Univ. Press; 1971. p. 71-181.

Jang J, Hur HG, Sadowsky MJ, Byappanahalli MN, Yan T, Ishii S. Environmental Escherichia coli: ecology and public health implications-a review. J Appl Microbiol. 2017;123(3):570-81.

Klovan JE, Imbrie J. An algorithm and FORTRAN-IV program for large-scale Qmode factor analysis and calculation of factor scores. Math Geol. 1971;3(1): 61-77.

Martin SA, Sullivan HM, Evans JD. Effect of sugars and malate on ruminal microorganisms. J Dairy Sci. 2000;83(11):2574-9.

Martin-Dominguez V, Estevez J, de Borja Ojembarrena F, Santos VE, Ladero M. Fumaric acid production: a biorefinery perspective. Fermentation. 2018:4(33). https://doi.org/10.3390/fermentation4020033.

Martínez-González S, Escalera-Valente F, Gómez-Danés AA, Plascencia A, LoyaOlguin JL, Ramírez-Ramírez JC, Barreras A, Valdés-García YS, Aguirre-Ortega J. Influence of levels of DL-malic acid supplementation on milk production and composition in lactating Pelibuey ewes and pre-weaning weight gain of their suckling kids. J Appl Anim Res. 2015;43(1):92-6.

Moon SY, Hong SH, Kim TY, Lee SY. Metabolic engineering of Escherichia coli for the production of malic acid. Biochem Eng J. 2008:40(2):312-20.

Nghiem NP, Kleff S, Schwegmann S. Succinic acid: technology development and commercialization. Fermentation. 2017;3(2):26. https://doi.org/10.3390/ fermentation3020026.

Sauer M, Porro D, Mattanovich D, Branduardi P. Microbial production of organic acids: expanding the markets. Trends Biotechnol. 2008;26(2):100-8.

Sharma A, Thakur S, Kumar V, Kanwar MK, Kesavan AK, Thukral AK, Bhardwaj R, Alam P, Ahmad P. Pre-sowing seed treatment with 24-epibrassinolide ameliorates pesticide stress in Brassica juncea L. through the modulation of stress markers. Front Plant Sci. 2016;7:1569.

Sieger R, Gersonde R, Zielinski U. New software package available for quantitative paleoenvironmental reconstructions. Eos, Transactions American Geophysical Union. 1999;80(19):223

Skorokhodova AY, Gulevich AY, Morzhakova AA, Shakulov RS, Debabov VG. Metabolic engineering of Escherichia coli for the production of succinic acid from glucose. Appl Biochem Microbiol. 2013;49(7):629-37.

Taguchi YH, Oono Y. Nonmetric multidimensional scaling as a data-mining tool: new algorithm and new targets. Geometrical Structures of Phase Space, Multidimensional Chaos, Adv Chem Phys. 2005;130:315-51.

Thakker C, Martínez I, San KY, Bennett GN. Succinate production in Escherichia coli. Biotechnol J. 2012;7(2):213-24.

Thakker C, San KY, Bennett GN. Production of succinic acid by engineered E. coli strains using soybean carbohydrates as feedstock under aerobic fermentation conditions. Bioresour Technol. 2013;130:398-405.

Toker C, Karhan M, Ulger S. Endogenous organic acid variations in different chickpea (Cicer arietinum L.) genotypes. Acta Agriculturae Scandinavica, Section B-Soil \& Plant Science. 2004;M54(1):42-4.

Unden G, Bongaerts J. Alternative respiratory pathways of Escherichia coli: energetics and transcriptional regulation in response to electron acceptors. Biochimica et Biophysica Acta (BBA)-Bioenergetics. 1997;1320(3):217-34.

Wang C, Liu Q, Yang WZ, Dong Q, Yang XM, He DC, Dong KH, Huang YX. Effects of malic acid on feed intake, milk yield, milk components and metabolites in early lactation Holstein dairy cows. Livest Sci. 2009;124(1-3):182-8. 